\title{
Differential and combined impacts of extreme temperatures and air pollution on human mortality in south-central Canada. Part I: historical analysis
}

\author{
Chad Shouquan Cheng • Monica Campbell • Qian Li • Guilong Li • Heather Auld • \\ Nancy Day • David Pengelly • Sarah Gingrich • Joan Klaassen • Don MacIver • \\ Neil Comer • Yang Mao • Wendy Thompson • Hong Lin
}

Received: 30 June 2008 / Accepted: 23 January 2009 /Published online: 18 February 2009

(C) The Author(s) 2009. This article is published with open access at Springerlink.com

\begin{abstract}
This paper forms the first part of an introduction to a synoptic weather typing approach to assess differential and combined impacts of extreme temperatures and air pollution on human mortality in south-central Canada, focusing on historical analysis (a companion paper-Part II focusing on future estimates). In this study, an automated synoptic weather typing procedure was used to identify weather types that have a marked association with high air pollution levels and temperature extremes, and facilitates assessments of the differential and combined health impacts of extreme temperatures and air pollution. Annual mean elevated mortality (when daily mortality exceeds the baseline) associated with extreme temperatures and acute exposures to air pollution, based on 1954-2000, was 1,082

C. S. Cheng $(\triangle) \cdot$ Q. Li $\cdot$ G. Li $\cdot$ J. Klaassen $\cdot$ N. Comer $\cdot$ H. Lin Atmospheric Science and Applications Unit,

Meteorological Service of Canada Branch-Ontario,

Environment Canada,

4905 Dufferin Street,

Toronto, ON, Canada M3H 5T4

e-mail: shouquan.cheng@ec.gc.ca

M. Campbell $\cdot$ N. Day $\cdot$ S. Gingrich

Toronto Public Health,

Toronto, Canada

H. Auld $\cdot$ D. MacIver

Adaptation and Impacts Research Division,

Science and Technology Branch, Environment Canada,

Toronto, Canada

D. Pengelly

Department of Medicine, McMaster University,

Hamilton, Canada

Y. Mao $\cdot$ W. Thompson

Public Health Agency of Canada,

Ottawa, Canada
\end{abstract}

[95\% confidence interval $(\mathrm{CI})$ of $1,017-1,147]$ for Montreal, 1,047 (CI 994-1,100) for Toronto, 462 (CI 438-486) for Ottawa, and 327 (CI 311-343) for Windsor. Of this annual mean elevated mortality, extreme temperatures are usually associated with roughly $20 \%$, while air pollution is associated with the remaining $80 \%$. Three pollutants (ozone, sulfur dioxide, and nitrogen dioxide) are associated with approximately $75 \%$ of total air pollution-related mortality across the study area. The remaining $25 \%$ is almost evenly associated with suspended particles and carbon monoxide, the other two pollutants addressed in this study. Of the five pollutants, ozone is most significantly associated with elevated mortality, making up one-third of the total air pollution-related mortality. $\mathrm{PM}_{2.5}$ and $\mathrm{PM}_{10}$ were not used as a measure of particulate in the study due to brief data records. The study results also suggest that, on the basis of daily mortality risks, extreme temperaturerelated weather presents a much greater risk to human health during heat waves and cold spells than air pollution. For example, in Montreal and Toronto, daily mean elevated mortality counts within the hottest weather type were twice as high as those within air pollution-related weather types.

Keywords Temperature - Air pollution - Human mortality · Synoptic weather typing $\cdot$ South-central Canada

\section{Introduction}

It is well known that air pollution has been strongly linked to human health problems, particularly in vulnerable populations such as the elderly, young children, and those suffering from cardio-respiratory conditions (World Health Organization 2004). For example, Judek et al. (2004) 
pointed out that the annual excess number of deaths associated with short-term and long-term exposure to air pollution was estimated to be 1,800 and 4,200, respectively, for eight Census Divisions in Canada with a population of 8.9 million (national total population of 30.0 million in the 2001 Census). Another report released by Toronto Public Health (2004) estimated that about 1,700 premature deaths each year in the City of Toronto (population $=2.5$ million in the 2001 Census) were associated with acute or short-term exposures to ozone $\left(\mathrm{O}_{3}\right)$, nitrogen dioxide $\left(\mathrm{NO}_{2}\right)$, carbon monoxide ( $\mathrm{CO})$, sulfur dioxide $\left(\mathrm{SO}_{2}\right)$, and chronic or longterm exposures to fine particulate matter $\left(\mathrm{PM}_{2.5}\right)$. About 700 of these deaths were attributable to acute exposures alone. The Ontario Medical Association (OMA 2005) estimated that, based on acute exposure to $\mathrm{O}_{3}, \mathrm{SO}_{2}, \mathrm{NO}_{2}$, $\mathrm{CO}$, and PM, air pollution causes approximately 5,800 premature deaths per year in Ontario (population $=11.4$ million in the 2001 Census) and almost $\$ 8$ billion in direct costs to the provincial health care system.

It is also well known that temperature extremes are responsible for significant numbers of deaths during hot and cold days. For example, a recent study (Medina-Ramón and Schwartz 2007) investigated the relationships between temperature extremes and mortality in 50 US cities, resulting in mortality increases associated to both extreme heat $(+5.74 \%)$ and extreme cold $(+1.59 \%)$. In the US, during the hot summer of 1980, an estimated 10,000 deaths were related to oppressive heat (Ross and Lott 2003). The severe 5-day heat wave over the central United States during mid-July 1995 caused 830 deaths, with 525 of these deaths in the City of Chicago (Changnon et al. 1996). During August 2003, western European countries experienced a record-breaking, heat-wave event; in France alone over 14,800 deaths may have been directly caused by this heat wave (Pirard et al. 2005).

Many chronic diseases, especially those of the respiratory and cardiovascular systems, are exacerbated most frequently during or after a period of specific weather conditions (e.g., Kalkstein 1991; Cheng 1991; Nichols et al. 1995; Sheridan and Kalkstein 2004; Shin et al. 2008) and/ or high air pollution concentrations (Schwartz et al. 1991; Burnett et al. 1994, 1999; Schwartz 2000, Basu and Ostro 2008). As shown in Table 1 for examples, a number of the previous studies in this field have examined how humanmade factors such as atmospheric pollutants affect human health; many others have focused on how natural stressors such as extreme temperatures influence death rates. Some other studies (e.g., Rainham and Smoyer-Tomic 2003; Hu et al. 2008) have investigated associations between extreme temperatures and mortality, considering confounding impacts of air pollutants. However, the differential and combined impacts of extreme temperature-related weather events and high air pollution episodes on human health are poorly understood. In the light of these concerns, Environment Canada, in partnerships with Toronto Public Health, McMaster University, Health Canada, and Public Health Agency of Canada, has completed a 3-year research project. This project, funded by the Health Policy Research Program, Health Canada, proposed a method based on synoptic weather typing in addition to air pollution levels to evaluate differential and combined impacts of extreme temperatures and air pollution on human mortality in southcentral Canada. The results from this study, expressed as elevated mortality (above the baseline) associated with different factors (e.g., heat, cold, pollutants), could be usable by governmental agencies and stakeholders for assisting in developing better policies on health protection and balancing policy decisions. This study may enhance current understanding of environmental problems related to human health in south-central Canada.

The current paper describes the background to the development of an analysis approach to quantitatively estimate elevated mortality, applying an automated synoptic weather typing and mortality baseline analyses. The synoptic weather typing has been adapted to develop a heat-health watch/warning system piloted in Philadelphia, Cincinnati, Rome, Shanghai, and Toronto for the UN Showcase Project (Sheridan and Kalkstein 2004). This method promises to evaluate relationships among a variety of weather elements rather than only individual variablesthe synergistic impact of several elements being more significant than the sum of their individual impacts (Kalkstein 1991; Pope and Kalkstein 1996; Kalkstein et al. 1997). Part of the current study focusing on climate change impacts analysis on both future air pollution- and temperature extreme-related mortality in south-central Canada is presented in a companion paper (Part II, Cheng et al. 2009). To effectively estimate climate change-induced future elevated mortality, historical analysis is essential for us to build a solid science foundation on health impacts of air pollution and extreme temperatures. For this study, four cities, Montreal, Ottawa, Toronto, and Windsor, located in south-central Canada, were selected (Fig. 1). There are several reasons for selection of the cities. First, the cities, especially for Windsor, have experienced the hottest weather situation in the country. Second, Toronto and Montreal are the two largest cities, in terms of population, in Canada. Finally, Ottawa is the capital of Canada.

\section{Data sources and treatment}

To evaluate differential and combined impacts of air pollution and extreme temperatures on human mortality, meteorological, air pollution, and mortality data are needed. The detailed information, regarding data sources, variables, 


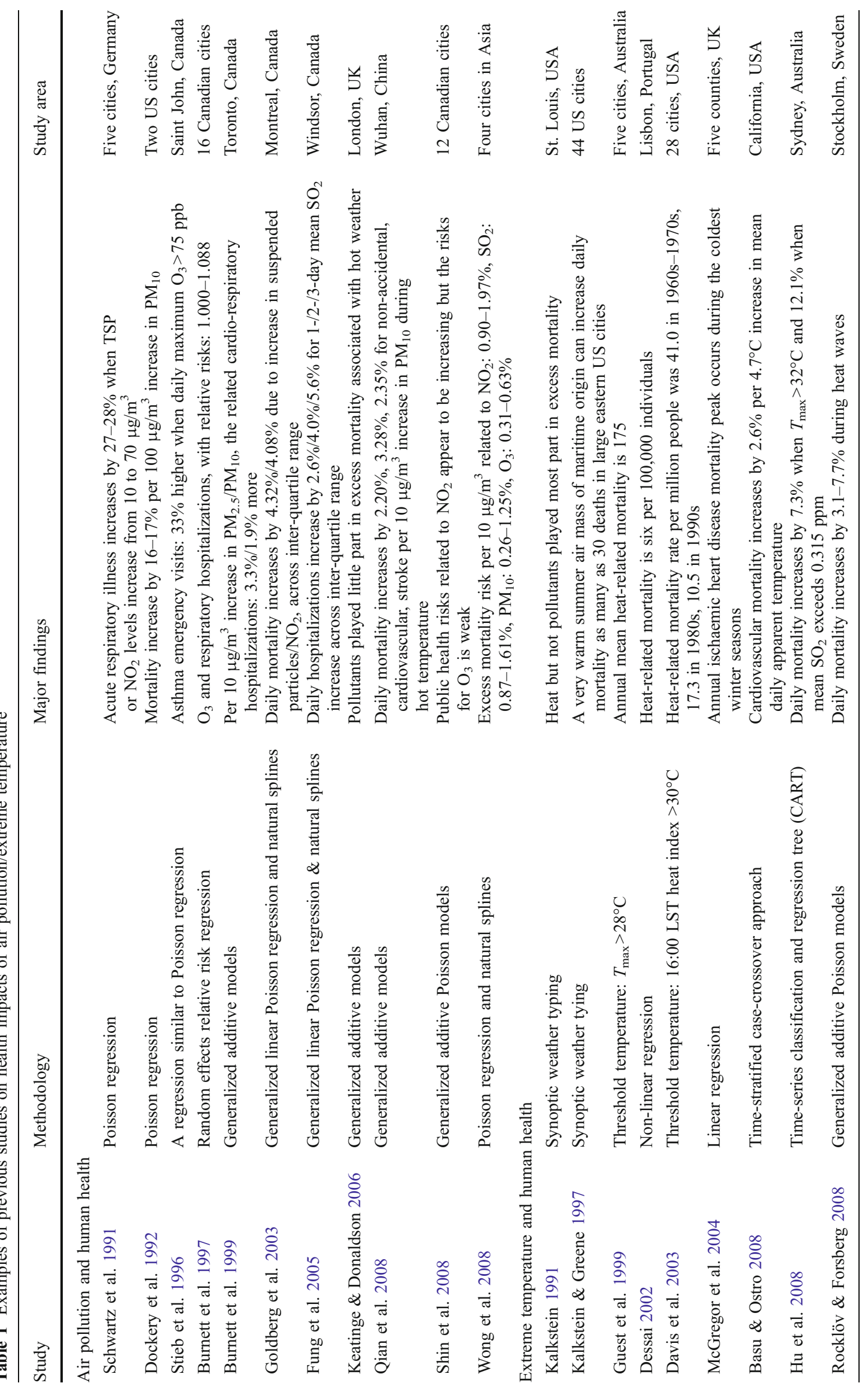


Fig. 1 Location map of the four selected cities

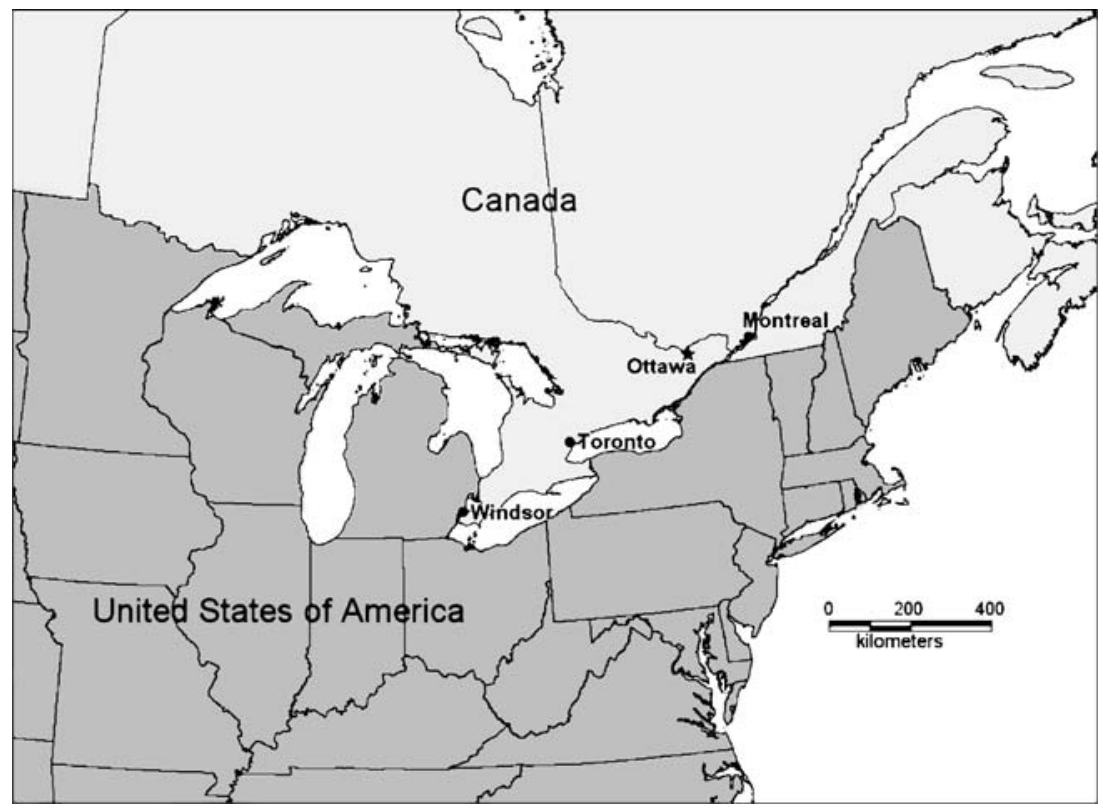

and record length, is described in Table 2. In this study, hourly surface meteorological data for the period 19542000 were used for the treatment of missing data. Missing data of each meteorological variable were interpolated using a temporal linear method in cases where the data were missing for three consecutive hours or less; days with data missing for four or more consecutive hours were excluded from the analysis. Of the total dataset, about $1 \%$ of the total days required missing data interpolation; after interpolation, the dataset was over $99.7 \%$ complete. Additionally, only six-hourly weather variables observed at 03:00, 09:00, 15:00, and 21:00 local standard time (LST) were used in the study. For air pollution data, several monitoring sites listed in Table 2, based on the length and completeness of the available data records, were chosen to calculate hourly/daily mean concentrations representing average air pollution conditions for each of the selected cities (refer to Cheng et al. 2007a for details on air pollution data treatment).

To effectively evaluate extreme temperature- and air pollution-related health risks, the daily aggregated nontraumatic mortality data have to be treated to remove inter-

Table 2 Data used in the study

\begin{tabular}{|c|c|c|c|}
\hline Description & Variable & Source & City \\
\hline \multicolumn{4}{|c|}{ Total non-traumatic mortality (1954-2000): } \\
\hline ICD-6 (1953-1957): 001-795 & \multirow[t]{5}{*}{ Daily aggregated mortality counts } & \multirow[t]{5}{*}{ Statistics Canada } & \multirow{5}{*}{$\begin{array}{l}\text { Montreal (Island) } \\
\text { Ottawa } \\
\text { Toronto (Metropolitan) } \\
\text { Windsor }\end{array}$} \\
\hline ICD-7 (1958-1968): 001-795 & & & \\
\hline ICD-8 (1969-1978): 000-796 & & & \\
\hline ICD-9 (1979-1999): 001-799 & & & \\
\hline ICD-10 (2000): A00-R99 & & & \\
\hline \multirow{5}{*}{$\begin{array}{l}\text { Six-hourly surface meteorological } \\
\text { observations at } 03: 00,09: 00, \\
\text { 15:00, 21:00 local standard } \\
\text { time }(1954-2000)\end{array}$} & Air temperature $\left({ }^{\circ} \mathrm{C}\right)$ & \multirow{5}{*}{$\begin{array}{l}\text { Environment Canada's National } \\
\text { Climate Data and } \\
\text { Information Archive }\end{array}$} & \multirow{5}{*}{$\begin{array}{l}\text { International airports in } \\
\text { Montreal, Ottawa, Toronto, } \\
\text { and Windsor }\end{array}$} \\
\hline & Dew point $\left({ }^{\circ} \mathrm{C}\right)$ & & \\
\hline & Sea-level air pressure $(\mathrm{hPa})$ & & \\
\hline & Total cloud cover (tenths) & & \\
\hline & U-wind and $\mathrm{V}$-wind $\left(\mathrm{m} \mathrm{s}^{-1}\right)$ & & \\
\hline \multicolumn{4}{|l|}{ Hourly/daily air pollution observations: } \\
\hline 1980-2000 for ozone & Carbon monoxide (CO) & \multirow{5}{*}{$\begin{array}{l}\text { Environment Canada's National } \\
\text { Air Pollution Surveillance } \\
\text { (NAPS) network }\end{array}$} & Monitoring stations: \\
\hline 1974-1996 for suspended particles & Nitrogen dioxide $\left(\mathrm{NO}_{2}\right)$ & & Montreal: 7 \\
\hline 1974-2000 for rest of pollutants & Ozone $\left(\mathrm{O}_{3}\right)$ & & Ottawa: 1 \\
\hline & Sulfur dioxide $\left(\mathrm{SO}_{2}\right)$ & & Toronto: 3 \\
\hline & Suspended particles (SP) & & Windsor: 2 \\
\hline
\end{tabular}


annual trends and seasonal fluctuations. The inter-annual trends over time for total non-traumatic mortality are shown in Fig. 2. These upward trends likely resulted from several factors, including increases in total population and changes in population age structure (Kalkstein et al. 1997). Other factors (i.e., improvements to health care and economic/ living conditions) could reduce the upward trends. Since this study attempts to analyze health impacts of extreme temperatures and air pollution, such non-environmental factors, representing confounding influences within the mortality data, should be removed. The mortality upward trends over time can be removed by fitting a polynomial regression line through annual mean mortality counts against time (in years), which is the baseline I shown in Fig. 2. It is noteworthy that the upward trend pattern for Montreal is different from that of other cities; this is a result of a decline in population (about 0.2 million) from 1971 to 1981, based on the census data of Statistics Canada. The residual or difference between each day's actual mortality count and the baseline count (Fig. 2) indicates that upward trends due to non-environmental factors have been removed. From removing non-environmental factors using the baseline I, some health impacts of extreme temperatures and air pollution were also removed since the extreme hot and polluted days were included in construction of the baseline I. The next step is to modify the baseline I to develop the baseline II using only weather types associated with relatively good air quality and comfortable weather conditions (see the section 'Results and discussion' for a detailed information).

In addition to inter-annual trends, the mortality seasonal fluctuations need to be removed from the analysis. Using monthly mortality baseline II, seasonal fluctuations can be excluded from mortality data by removing monthly interannual trends. The monthly mortality baseline II was developed by fitting monthly polynomial regression models, which usually explain over $80 \%$ of the data variances for the four selected cities. In addition to inter-annual and seasonal fluctuations of mortality, consideration was given to removing weekly fluctuations of mortality from the data.
Fig. 2 Inter-annual total nontraumatic mortality trends (baseline I). The $x$ described in equations is set as 1 for the year 1954, 2 for 1955, and so on
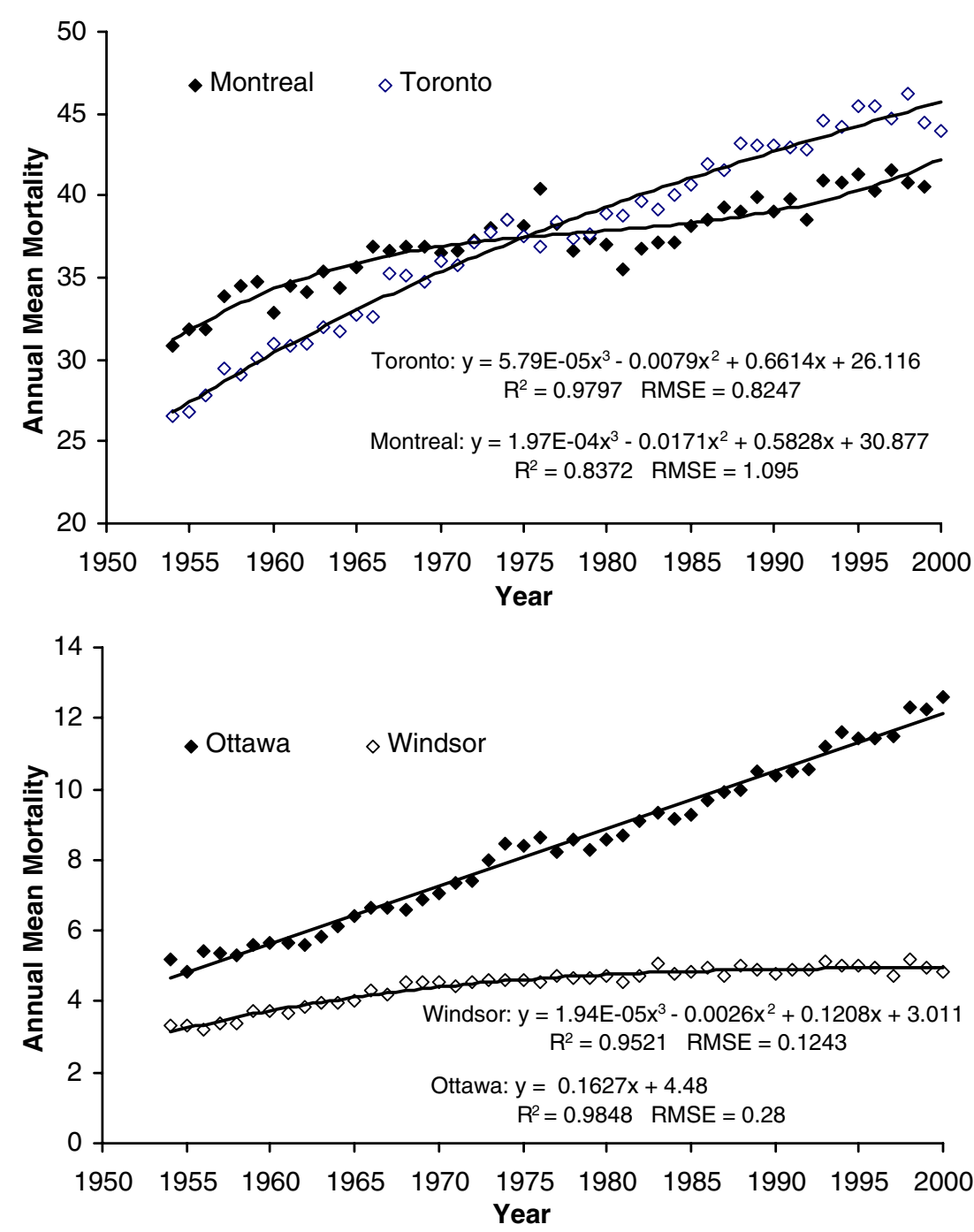
However, the weekly fluctuations within a weather group were not statistically significant for the four selected cities and therefore were not considered to be removed.

\section{Analysis techniques}

To analyze differential and combined impacts of extreme temperatures and air pollution on human health, three major methods or steps are used in the study. First, an automated synoptic weather typing was employed to classify each day of the dataset into a distinctive weather type based on weather characteristics represented by a variety of weather variables. Second, daily air pollution data were used to identify the weather types most highly associated with high air pollution levels for each of the pollutants. Finally, temperature extreme- and air pollution-related mortality could be distinguished by linking daily elevated mortality (above the baseline) with hot/cold/air pollution-related synoptic weather types. The detailed information on analysis techniques is summarized in Fig. 3.

\section{Synoptic weather typing}

An automated synoptic weather typing, based primarily on air mass similarity and differentiation within and between weather types, was used to assign each day of the dataset to a distinctive weather type. The entire suite of 24 weather variables, including six-hourly surface weather observations of air temperature, dew point temperature, sea-level air pressure, total cloud cover, and south-north and westeast winds, were used in synoptic weather typing. As part of this research, Cheng et al. (2007a, 2007b) have developed weather typing procedures for evaluation of climate change impacts on air pollution concentrations for the selected four cities, which were also used in this study. Due to space limitation, weather typing procedures are briefly summarized here. Weather typing procedures are

Fig. 3 Flow chart of methodologies and steps used in the study
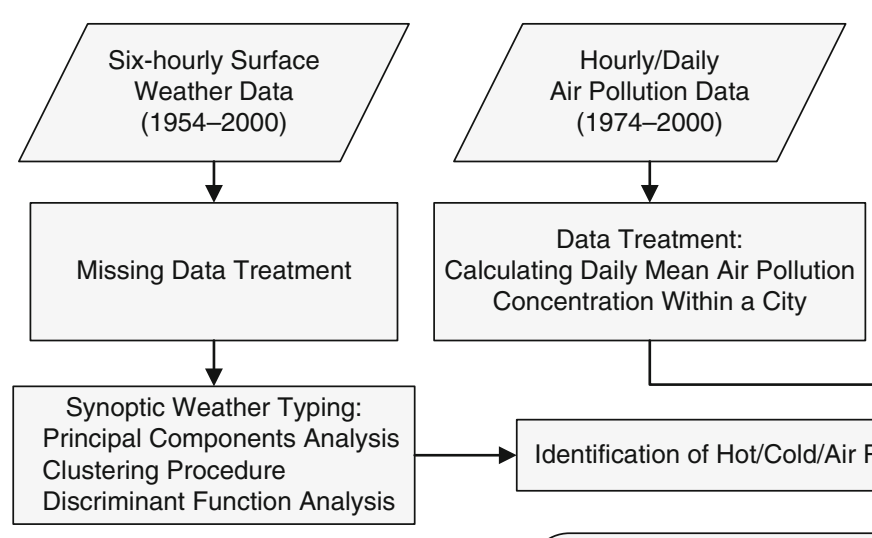

Data Treatment:

Calculating Daily Mean Air Pollution Concentration Within a City

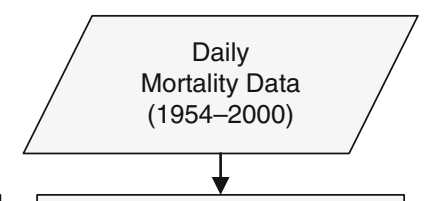

Data Treatment: Mortality Baseline to Remove Inter-annual Trends and Seasonal Fluctuation

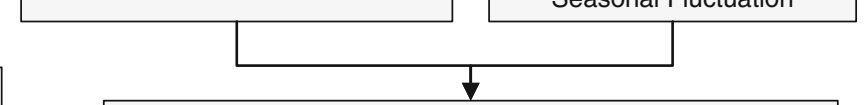

Identification of Hot/Cold/Air Pollution-related Weather Types

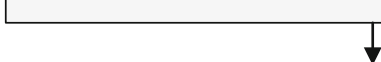

Evaluation of Hot-/Cold-/Air Pollution-related Health Risks 
air pollution concentrations for each of the selected pollutants. As shown in Table 3, two measurements, within-weather-type mean air pollution concentrations and frequency of high air pollution episodes, were used to determine relationships between weather types and air quality. Daily mean air pollution concentrations for each type were then determined to ascertain whether the air pollution levels within the particular weather types were distinctively high or low. In addition, a ratio of the withinweather-type occurrence of high air pollution episodes (actual frequency) to the occurrence of the weather type in the entire record (expected frequency) was utilized to determine whether any of the weather types were overrepresented for high air pollution episodes. Weather types with ratios significantly greater than 1.0 clearly had a greater proportion of days with high air pollution episodes than would be expected. If the frequency ratio was greater than 1.0 and the within-weather-type mean concentration was higher than the overall mean, that weather type was selected as an air pollution-related weather type. As shown in Table 3 for Toronto, nine weather types were defined as the $\mathrm{O}_{3}$-related types. A $\chi^{2}$ test was used to ascertain whether the actual frequencies of high air pollution events (daily air pollution concentration with one, two, and three

Table 3 Within-weather-type $\mathrm{O}_{3}$ level by concentration anomalies (overall mean=17.0 ppb) for nine $\mathrm{O}_{3}$-related weather types (types $1-9$ ) and examples of nine low- $\mathrm{O}_{3}$-level types (types 17-25) in Toronto (1980-2000)

\begin{tabular}{|c|c|c|c|c|c|c|c|c|c|c|c|c|}
\hline \multicolumn{3}{|c|}{ Synoptic type } & \multicolumn{10}{|c|}{$\mathrm{O}_{3}$ concentration level } \\
\hline & & & \multirow{2}{*}{$\begin{array}{l}\text { Mean }^{2} \\
(\mathrm{ppb})\end{array}$} & \multicolumn{3}{|c|}{1 std. dev. above mean } & \multicolumn{3}{|c|}{2 std. dev. above mean } & \multicolumn{3}{|c|}{3 std. dev. above mean } \\
\hline Type & Days & $\begin{array}{l}\text { Freq. } \\
(\%)^{1}(a)\end{array}$ & & Days & $\begin{array}{l}\text { Freq. } \\
(\%)^{3}(\mathrm{~b})\end{array}$ & $\begin{array}{l}\text { Ratio }^{4} \\
\text { (b)/(a) }\end{array}$ & Days & $\begin{array}{l}\text { Freq. } \\
(\%)^{3} \text { (c) }\end{array}$ & $\begin{array}{l}\text { Ratio }^{4} \\
\text { (c)/(a) }\end{array}$ & Days & $\begin{array}{l}\text { Freq. } \\
(\%)^{3}(d)\end{array}$ & $\begin{array}{l}\text { Ratio }^{4} \\
\text { (d)/(a) }\end{array}$ \\
\hline 1 & 173 & 2.26 & 32.02 & 130 & 11.76 & 5.21 & 74 & 18.78 & 8.31 & 21 & 19.09 & 8.45 \\
\hline 2 & 223 & 2.91 & 26.14 & 136 & 12.31 & 4.23 & 62 & 15.74 & 5.40 & 23 & 20.91 & 7.18 \\
\hline 3 & 260 & 3.40 & 28.47 & 186 & 16.83 & 4.96 & 83 & 21.07 & 6.20 & 23 & 20.91 & 6.16 \\
\hline 4 & 233 & 3.04 & 19.77 & 115 & 10.41 & 3.42 & 45 & 11.42 & 3.75 & 12 & 10.91 & 3.59 \\
\hline 5 & 161 & 2.10 & 21.87 & 88 & 7.96 & 3.79 & 37 & 9.39 & 4.47 & 12 & 10.91 & 5.19 \\
\hline 6 & 107 & 1.40 & 15.94 & 40 & 3.62 & 2.59 & 12 & 3.05 & 2.18 & 5 & 4.55 & 3.25 \\
\hline 7 & 81 & 1.06 & 15.30 & 35 & 3.17 & 2.99 & 8 & 2.03 & 1.92 & 1 & 0.91 & 0.86 \\
\hline 8 & 348 & 4.54 & 5.19 & 64 & 5.79 & 1.27 & 12 & 3.05 & 0.67 & 1 & 0.91 & 0.20 \\
\hline 9 & 285 & 3.72 & 8.36 & 64 & 5.79 & 1.56 & 13 & 3.30 & 0.89 & 1 & 0.91 & 0.24 \\
\hline 17 & 270 & 3.53 & -13.68 & 0 & 0.00 & 0.00 & 0 & 0.00 & 0.00 & 0 & 0.00 & 0.00 \\
\hline 18 & 235 & 3.07 & -11.72 & 0 & 0.00 & 0.00 & 0 & 0.00 & 0.00 & 0 & 0.00 & 0.00 \\
\hline 19 & 125 & 1.63 & -11.54 & 1 & 0.09 & 0.06 & 0 & 0.00 & 0.00 & 0 & 0.00 & 0.00 \\
\hline 20 & 138 & 1.80 & -15.99 & 1 & 0.09 & 0.05 & 0 & 0.00 & 0.00 & 0 & 0.00 & 0.00 \\
\hline 21 & 70 & 0.91 & -11.29 & 0 & 0.00 & 0.00 & 0 & 0.00 & 0.00 & 0 & 0.00 & 0.00 \\
\hline 22 & 304 & 3.97 & -15.70 & 1 & 0.09 & 0.02 & 0 & 0.00 & 0.00 & 0 & 0.00 & 0.00 \\
\hline 23 & 110 & 1.44 & -9.95 & 0 & 0.00 & 0.00 & 0 & 0.00 & 0.00 & 0 & 0.00 & 0.00 \\
\hline 24 & 203 & 2.65 & -16.80 & 2 & 0.18 & 0.07 & 0 & 0.00 & 0.00 & 0 & 0.00 & 0.00 \\
\hline 25 & 174 & 2.27 & -11.04 & 0 & 0.00 & 0.00 & 0 & 0.00 & 0.00 & 0 & 0.00 & 0.00 \\
\hline Sub-total $1^{5}$ & 2,114 & 27.61 & 18.31 & 973 & 88.05 & 3.19 & 385 & 97.72 & 3.53 & 110 & 100 & 3.62 \\
\hline Total $^{6}$ & 7,655 & & & 1,105 & & & 394 & & & 110 & & \\
\hline
\end{tabular}

\footnotetext{
${ }^{1}$ Percentage occurrence of the weather type or expected frequency for high $\mathrm{O}_{3}$-level events (within-weather-type number of days divided by the number of total days)

${ }^{2}$ Within-weather-type daily mean anomalies of $\mathrm{O}_{3}$ concentrations (overall mean $=17.0 \mathrm{ppb}$ )

${ }^{3}$ Percentage occurrence (actual frequency) of the days with one, two, and three standard deviations above the overall mean (17.0 ppb) within a particular weather type (within-weather-type number of the events divided by the number of total events)

${ }^{4}$ Ratio of actual frequency of the high $\mathrm{O}_{3}$-level events over the expected frequency. A ratio greater than one indicates that a larger proportion of days in the weather type possess higher $\mathrm{O}_{3}$ levels than would be expected

${ }^{5}$ The sum of the nine $\mathrm{O}_{3}$-related weather types and some small weather types that are most associated with high $\mathrm{O}_{3}$ concentration levels, but not shown in Table 4

${ }^{6}$ The sum of all weather types
} 
standard deviations above the overall mean) were significantly different from their expected occurrences $\left(\chi^{2}\right.$ test significance level of 0.001). This method was then applied to different pollutants for each of the selected cities.

Health impacts of extreme temperatures and air pollution

Synoptic weather typing can be used to evaluate the differential and combined impacts of extreme temperatures and air pollution on elevated mortality. In this study, the elevated mortality counts within the weather types associated with high air pollution concentrations - but with comfortable weather conditions - are treated as the impacts of air pollution on human health. The impacts of extreme temperatures on human health might be determined by the hot and cold weather types. Although the hot/cold weather groups are usually associated with high air pollution concentrations, elevated mortality within the hot/cold groups was defined as extreme temperature-related mortality since extreme temperatures are most relevant to elevated mortality in these weather groups (refer to the section 'Results and discussion' for a more detailed information).

The synoptic weather typing procedure can be used to analyze differential impacts of air pollutants on elevated mortality counts as well. The air pollution-related weather types may be associated with high air pollution concentrations for one single pollutant or multiple pollutants. For the former case, within-weather-type elevated mortality can be identified as associated with that particular pollutant. For the latter case, the study assumes that within-weather-type elevated mortality is associated with the one particular pollutant that is most important to the weather type (refer to the section 'Results and discussion' for a more detailed information).

Consideration was given to taking into account lag times of extreme temperature and air pollution impacts on mortality. Based on the analysis, no-lag-time relationships between heat and mortality are more significant than other lag times across the study area. This is consistent with the previous studies (e.g., Dessai 2002; Rainham and SmoyerTomic 2003; Sheridan and Kalkstein 2004). As a result, the within-weather-type elevated mortality was estimated in the study based on lag-zero-day relationships.

\section{Results and discussion}

Findings derived from this study are significant in three areas: (1) extreme temperature- and air pollution-related weather types, (2) mortality baseline, and (3) differential and combined health impacts of temperature extremes and air pollution. The major findings in each of the areas are discussed in this section as follows.
Extreme temperature- and air pollution-related weather types

The number of major synoptic weather types (with sizes above $1 \%$ of the total days) identified for the selected cities varied slightly from one city to another: $39,37,36$, and 39 for Montreal, Ottawa, Toronto, and Windsor, respectively. The smaller weather types were still included in the analysis. As part of this study, Cheng et al. (2007a) have determined extreme temperature- and air pollution-related weather types for the selected cities. For each of the four selected cities, there are three hot weather types, four or five cold weather types, and the number of air pollutionrelated weather types, as shown in Table 4 for Toronto (similar results were discovered for the other cities as well, but not shown). The three hot weather types (Hot1, Hot2, and Hot3) can capture $50-60 \%, 20-30 \%$, and about $10 \%$ of the total days with $15: 00$ LST temperature $\geq 32^{\circ} \mathrm{C}$, respectively, across the study area. For determination of the cold weather types, the criterion varies from location to location, based on the difference of January mean 15:00 temperature among the cities. The within-weather-type mean 15:00 temperature of $\leq-6^{\circ} \mathrm{C}$ was used to define a cold weather type for Ottawa and Montreal, and of $\leq-3^{\circ} \mathrm{C}$ for Toronto and Windsor.

As described in the previous section, air pollution-related weather types were defined based on (1) within-weather-type daily mean concentrations and (2) the ratios of actual frequency of high pollution level events over the expected frequency. The within-weather-type mean concentrations and ratios for nine $\mathrm{O}_{3}$-related weather types and nine low$\mathrm{O}_{3}$-level types in Toronto are shown in Table 3, as an example. The similar results were found for other selected cities but not shown due to limitations of space. As shown in Table 3, daily mean anomalies of $\mathrm{O}_{3}$ concentration within weather types 1-9 are much higher than the overall mean (17.0 ppb in Toronto). Most of other weather types (e.g., weather types 17-25) possess negative mean anomalies of $\mathrm{O}_{3}$ concentrations. For weather type 1 in Toronto, the expected frequency of high air pollution events would be $2.26 \%$, based on the size of the weather type. However, the actual frequency of the high air pollution events with one and three standard deviations above the overall mean was about $12 \%$ and $19 \%$, respectively-more than five and eight times what might otherwise be expected. Through these analyses, ten, nine, nine, and nine $\mathrm{O}_{3}$-related weather types were identified for Montreal, Ottawa, Toronto, and Windsor, respectively, of which the first three are also called hot weather types. On average across the four selected cities, these weather types accounted for $83 \%$ and $97 \%$ of the total high $\mathrm{O}_{3}$ events with greater than one and three standard deviations above the overall mean, respectively. 
Table 4 Ten weather groups in Toronto: three hot, one cold, five air pollutant-related, and one "other"

\begin{tabular}{|c|c|c|c|c|c|c|c|c|c|c|c|c|}
\hline \multirow{2}{*}{$\begin{array}{l}\text { Type } \\
1\end{array}$} & \multicolumn{2}{|c|}{$\begin{array}{l}\text { 15:00 LST temperature } \\
\text { (std. dev.) }\end{array}$} & \multicolumn{2}{|c|}{$\begin{array}{l}\text { 15:00 LST dew point } \\
\text { (std. dev.) }\end{array}$} & \multicolumn{2}{|c|}{$\begin{array}{l}\text { 15:00 LST wind } \\
\text { speed/direction }\end{array}$} & \multicolumn{5}{|c|}{$\begin{array}{l}\text { Pollutants associated with weather } \\
\text { types }\end{array}$} & \multirow{2}{*}{$\begin{array}{l}\text { Weather groups } \\
\text { Hot1/AP }\end{array}$} \\
\hline & 29.82 & $(2.73)$ & 17.37 & $(3.21)$ & 5.63 & WSW & $\mathrm{O}_{3}$ & & $\mathrm{NO}_{2}$ & SP & & \\
\hline 2 & 27.23 & $(3.11)$ & 16.44 & $(3.42)$ & 6.31 & WSW & $\mathrm{O}_{3}$ & $\mathrm{SO}_{2}$ & $\mathrm{NO}_{2}$ & SP & & Hot2/AP \\
\hline 3 & 26.78 & $(2.63)$ & 14.35 & $(3.38)$ & 5.05 & $\mathrm{~S}$ & $\mathrm{O}_{3}$ & $\mathrm{SO}_{2}$ & $\mathrm{NO}_{2}$ & SP & & Hot3/AP \\
\hline 4 & 24.58 & $(3.04)$ & 18.49 & $(2.16)$ & 3.95 & $\mathrm{~S}$ & $\mathrm{O}_{3}$ & & $\mathrm{NO}_{2}$ & SP & & $\mathrm{AP}-\mathrm{O}_{3}$ \\
\hline 5 & 24.45 & $(3.04)$ & 15.14 & $(3.39)$ & 4.58 & $\mathrm{~S}$ & $\mathrm{O}_{3}$ & $\mathrm{SO}_{2}$ & $\mathrm{NO}_{2}$ & SP & $\mathrm{CO}$ & $\mathrm{AP}-\mathrm{O}_{3}$ \\
\hline 6 & 23.04 & $(2.91)$ & 9.45 & $(3.74)$ & 4.53 & SSE & $\mathrm{O}_{3}$ & & $\mathrm{NO}_{2}$ & SP & $\mathrm{CO}$ & $\mathrm{AP}-\mathrm{O}_{3}$ \\
\hline 7 & 25.03 & $(2.35)$ & 13.26 & $(2.97)$ & 3.30 & $\mathrm{SE}$ & $\mathrm{O}_{3}$ & & & & & $\mathrm{AP}-\mathrm{O}_{3}$ \\
\hline 8 & 19.31 & $(3.27)$ & 11.99 & $(3.22)$ & 3.78 & ESE & $\mathrm{O}_{3}$ & & $\mathrm{NO}_{2}$ & & & $\mathrm{AP}-\mathrm{O}_{3}$ \\
\hline 9 & 21.03 & $(3.14)$ & 7.64 & $(3.65)$ & 4.08 & SSE & $\mathrm{O}_{3}$ & & $\mathrm{NO}_{2}$ & & $\mathrm{CO}$ & $\mathrm{AP}-\mathrm{O}_{3}$ \\
\hline 10 & 16.64 & $(3.60)$ & 11.95 & $(3.47)$ & 4.25 & $\mathrm{SE}$ & & & $\mathrm{NO}_{2}$ & & & $\mathrm{AP}-\mathrm{NO}_{2}$ \\
\hline 11 & 13.17 & $(3.74)$ & 3.74 & $(3.52)$ & 4.13 & SE & & & $\mathrm{NO}_{2}$ & & $\mathrm{CO}$ & $\mathrm{AP}-\mathrm{NO}_{2}$ \\
\hline 12 & 0.92 & $(3.03)$ & -3.46 & $(2.87)$ & 5.90 & W & & $\mathrm{SO}_{2}$ & & & & $\mathrm{AP}-\mathrm{SO}_{2}$ \\
\hline 13 & 8.73 & $(4.61)$ & 0.63 & $(3.61)$ & 5.27 & W & & $\mathrm{SO}_{2}$ & $\mathrm{NO}_{2}$ & SP & $\mathrm{CO}$ & AP-SP \\
\hline 14 & 3.63 & $(3.55)$ & -0.10 & $(3.14)$ & 6.32 & WSW & & $\mathrm{SO}_{2}$ & & $\mathrm{SP}$ & $\mathrm{CO}$ & $\mathrm{AP}-\mathrm{SO}_{2}$ \\
\hline 15 & 2.55 & $(4.75)$ & -1.74 & $(4.14)$ & 8.51 & WSW & & $\mathrm{SO}_{2}$ & & & & $\mathrm{AP}-\mathrm{SO}_{2}$ \\
\hline 16 & 5.32 & $(3.90)$ & 0.46 & $(3.59)$ & 3.27 & $\mathrm{SE}$ & & $\mathrm{SO}_{2}$ & $\mathrm{NO}_{2}$ & SP & $\mathrm{CO}$ & $\mathrm{AP}-\mathrm{NO}_{2}$ \\
\hline 17 & 7.71 & $(3.76)$ & 4.23 & $(3.43)$ & 3.78 & SSE & & $\mathrm{SO}_{2}$ & $\mathrm{NO}_{2}$ & SP & $\mathrm{CO}$ & AP-SP \\
\hline 18 & -2.48 & $(2.96)$ & -5.67 & $(3.12)$ & 5.22 & ENE & & $\mathrm{SO}_{2}$ & & & & $\mathrm{AP}-\mathrm{SO}_{2}$ \\
\hline 19 & 16.23 & $(4.10)$ & 10.53 & $(3.65)$ & 5.54 & SW & & $\mathrm{SO}_{2}$ & $\mathrm{NO}_{2}$ & SP & $\mathrm{CO}$ & AP-SP \\
\hline 20 & 12.75 & $(5.65)$ & 2.96 & $(5.25)$ & 4.27 & SSE & & & & & $\mathrm{CO}$ & AP-CO \\
\hline 21 & -1.10 & $(4.38)$ & -8.29 & $(3.42)$ & 5.27 & NNW & & & & & $\mathrm{CO}$ & AP-CO \\
\hline 22 & -2.87 & $(3.23)$ & -8.03 & $(3.30)$ & 3.81 & SSW & & $\mathrm{SO}_{2}$ & $\mathrm{NO}_{2}$ & SP & $\mathrm{CO}$ & $\mathrm{AP}-\mathrm{SO}_{2}$ \\
\hline 23 & -5.25 & $(3.39)$ & -9.64 & $(3.67)$ & 6.76 & NNW & & & & & & Cold \\
\hline 24 & -10.44 & $(3.55)$ & -14.66 & $(3.83)$ & 4.81 & $\mathrm{~N}$ & & $\mathrm{SO}_{2}$ & $\mathrm{NO}_{2}$ & SP & $\mathrm{CO}$ & Cold/AP \\
\hline 25 & -9.77 & $(4.39)$ & -16.03 & $(4.20)$ & 4.06 & NNW & & $\mathrm{SO}_{2}$ & $\mathrm{NO}_{2}$ & & $\mathrm{CO}$ & Cold/AP \\
\hline 26 & -7.07 & $(3.55)$ & -12.15 & $(3.71)$ & 7.93 & W & & $\mathrm{SO}_{2}$ & & & & Cold/AP \\
\hline 27 & -2.97 & (3.98) & -7.60 & $(3.95)$ & 5.16 & SW & & $\mathrm{SO}_{2}$ & & SP & $\mathrm{CO}$ & Cold/AP \\
\hline 28 & 20.66 & $(3.33)$ & 8.76 & $(3.50)$ & 6.72 & WNW & & & & & & Other \\
\hline 29 & 23.01 & $(3.68)$ & 15.38 & $(3.00)$ & 6.04 & WNW & & & & & & Other \\
\hline 30 & 21.13 & $(3.09)$ & 8.76 & $(3.14)$ & 5.68 & NNW & & & & & & Other \\
\hline 31 & 11.75 & $(4.03)$ & -1.55 & $(3.67)$ & 5.34 & NW & & & & & & Other \\
\hline 32 & 7.79 & $(4.13)$ & -0.51 & $(3.87)$ & 7.29 & WNW & & & & & & Other \\
\hline 33 & 3.37 & $(3.64)$ & -1.97 & $(3.15)$ & 5.28 & NNW & & & & & & Other \\
\hline 34 & 2.71 & $(3.80)$ & 0.42 & $(3.68)$ & 6.55 & $\mathrm{E}$ & & & & & & Other \\
\hline 35 & 2.39 & $(4.17)$ & 0.44 & $(4.22)$ & 5.23 & $\mathrm{~N}$ & & & & & & Other \\
\hline 36 & -2.22 & $(4.38)$ & -6.64 & $(4.39)$ & 9.53 & WNW & & & & & & Other \\
\hline
\end{tabular}

Similar analyses were also applied to the remainder of the pollutants for each of the selected cities. The summarized results of the weather types highly associated with each of the pollutants are shown in Table 4 (using Toronto as an example). Some weather types showed significant linkage with high air pollution concentrations for many pollutants (up to five); other types possessed good air quality and were not significantly related to any pollutant. If a weather type was associated with high air pollution levels for more than one pollutant, it was important to determine which air pollutant was most significantly associated with the weather type, based on the highest weather-type-frequency ratio described in the section ('Analysis techniques') above. For example, 16 weather types are associated with relative high $\mathrm{SO}_{2}$ levels in Toronto; however, only five of them are most significantly related to $\mathrm{SO}_{2}$, while for the rest of the weather types, other pollutants are more important. As shown in Table 4, weather types for this study were divided into ten groups: three hot weather-related (including air pollution) groups (Hot1/AP, Hot2/AP, Hot3/AP), one cold weather-related (including air pollution) group (Cold/AP), five air 
pollutant-related groups $\left(\mathrm{CO}, \mathrm{NO}_{2}, \mathrm{O}_{3}, \mathrm{SO}_{2}, \mathrm{SP}\right)$, and one "other" group with relatively good air quality and comfortable weather conditions. For each of the four cities being studied, the percentage occurrences of the ten weather groups are fairly consistent across the study area, with only a small variation (Fig. 4). Such weather grouping can facilitate the analysis of differential and combined impacts of extreme temperatures and air pollution on human mortality.

\section{Mortality baseline}

The inter-annual upward trends over time for total nontraumatic mortality (mortality baseline I) shown in Fig. 2 were removed to minimize confounding influences of nonenvironmental factors (e.g., increases in total population and changes in population age structure). However, to quantitatively assess elevated mortality (above the baseline) associated with extreme temperatures and air quality, the mortality baseline I needs to be modified. Following determination of the ten weather groups, mortality baseline I can be adjusted to develop baseline II using only the "other" weather group. In fact, some low-frequency weather types not shown in Table 4, which were identified as "other," were also included in the development of baseline II. Baseline II was developed by calculating the within-"other"-weather-group mean mortality from anomalous data against baseline I for each 3-month season (December-February, March-May, June-August, September-November). As shown in Fig. 5 for Toronto as an example (similar results were discovered in other cities), baseline II was lower than baseline I since baseline I includes all days (including hot/cold/high air pollution episodes) in its construction. The difference between two baselines that represents part of the extreme temperatures and air pollution effects, which was removed from baseline I, should be added back to the elevated mortality. As a result, the baseline II can represent normal or natural deaths without the effects of extreme temperatures and air pollution. A positive mortality residual (above baseline II) should represent the elevated mortality associated with extreme temperatures and air pollution. A negative mortality residual (below baseline II) indicates a situation with no elevated mortality relative to extreme temperatures and air pollution. When within-weather-type annual and daily mean elevated mortalities were calculated, the daily negative mortality residual was set as zero.

The advantage of using the mortality baseline, as derived for the current study, is its enhancement of the relationship between extreme temperatures/air pollution and mortality. It could also minimize the confounding impacts of nonenvironmental factors such as population increase and improvements to health care and living/economic conditions. In the health studies, mortality rates were often used to remove the impacts of population growth. When longterm health data (e.g., ten-year spans of data records or more) are considered, it is insufficient to remove only population effects from mortality data so as to analyze health impacts of air pollution and extreme temperatures. To demonstrate this, population census data were used and tested to calculate mortality rates for the selected four cities. To effectively remove impacts of population increase and changes in population age structure, an elderly population ( $\geq 65$ years) was used. According to the results, there appears to be a significant downward trend in mortality rates for each of the cities, due to improvements to health care and living/economic conditions (e.g., use of air conditioning). On average, across the selected four cities, daily mean mortality rates per 100,000 elderly people were about 30 in the early 1950 s, dropping to 15 by the year 2000. For reliable, long-term, time-series health data, this downward trend should also be removed in order to prevent these non-environmental factors from influencing results.
Fig. 4 Percentage occurrence of the ten weather groups in the four cities (HA1, HA2, and HA3 represent the three hot weather groups; $C A$ is the cold weather group; $\mathrm{O}_{3}, \mathrm{NO}_{2}, \mathrm{SO}_{2}, \mathrm{CO}$, and $S P$ are different pollutant-related weather groups; and $O T$ is the "other" or comfortable weather group)

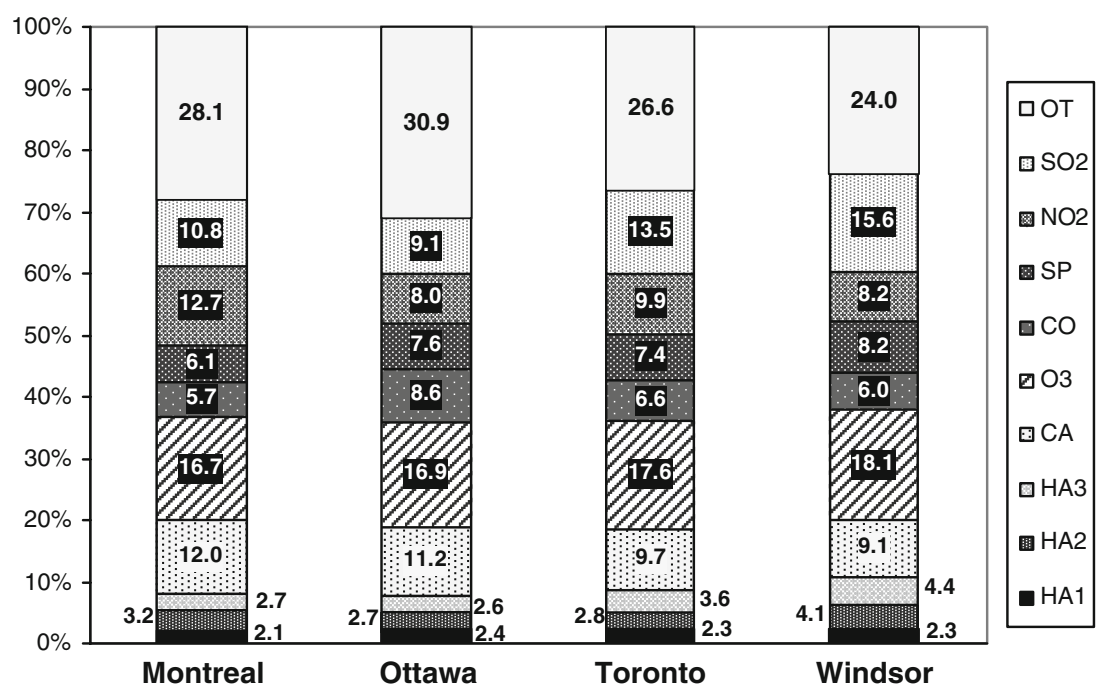




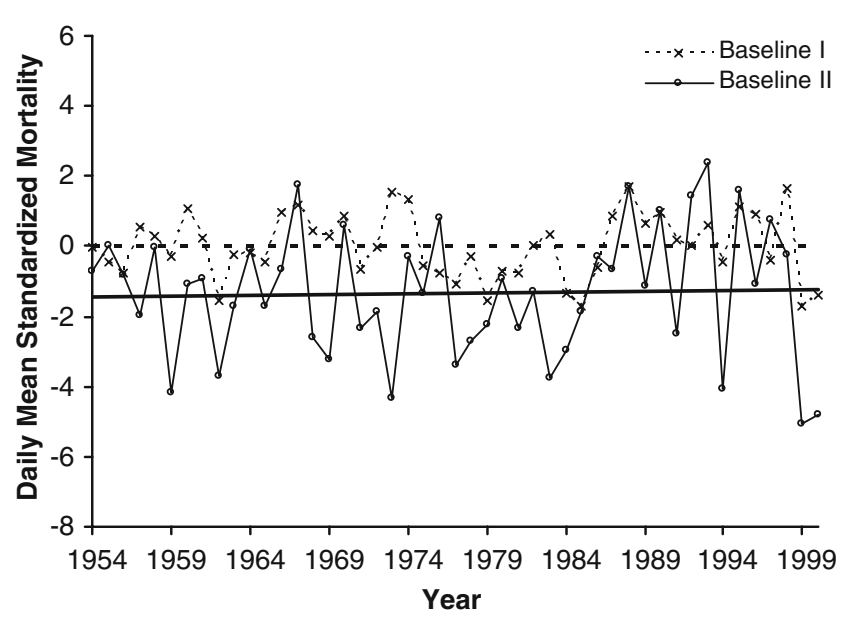

Fig. 5 Sample of mortality baselines I and II for summer season (June-August) in Toronto

Health impacts of temperature extremes and air pollution

Figure 6 shows quantitatively summarized results of the differential and combined impacts of extreme temperatures and air pollution on elevated non-traumatic mortality for the four selected cities. A mean annual total elevated mortality was calculated from the sum of positive mortality residuals for all days within each of the ten weather groups, divided by the total number of years. Generally, the proportion of elevated mortality associated with extreme temperatures and air pollution was consistent across the study area. Extreme temperatures were usually associated with over $20 \%$ of mean annual total elevated mortality; air pollution was related to the remaining $80 \%$. Of air pollution-related mortality, three pollutants $\left(\mathrm{O}_{3}, \mathrm{SO}_{2}\right.$, and $\left.\mathrm{NO}_{2}\right)$ were associated with about $75 \%$ across the study area. The remaining $25 \%$ was almost evenly associated with SP and $\mathrm{CO}$, the other two pollutants used in the study. Of the five pollutants, $\mathrm{O}_{3}$ was the most highly associated with elevated mortality in each of the cities, responsible for one-third of the total air pollution-related mortality.

Although "other" weather group is usually associated with relatively good air quality and comfortable weather conditions, there still exists some degree of within-type variance. The elevated mortality within the "other" weather group was still found to be associated with air pollution. To demonstrate this, days within the "other" weather group were divided into air pollution concentration deciles for each pollutant; the daily mean mortality was then calculated for each of the deciles. The results of the decile evaluation indicated that in the "other" weather group, there were significant relationships between air pollution concentrations and elevated mortality counts across the study area. Within-decile mean mortality residuals in the bottom deciles were usually lower than those of the top deciles for all pollutants except for CO. In addition to this decile analysis, within-"other"-weather-group regression results also show that only air pollutants other than weather variables are significantly associated with elevated mortality, with a model $R^{2}$ of $0.71,0.62,0.40$, and 0.30 for Montreal, Ottawa, Windsor and Toronto, respectively (refer to a companion paper-Part II, Cheng et al. 2009 for details on regression). This finding is consistent with that of previous studies (Lambert et al. 1998; Toronto Public Health 2001; Vedal et al. 2003), which concluded that

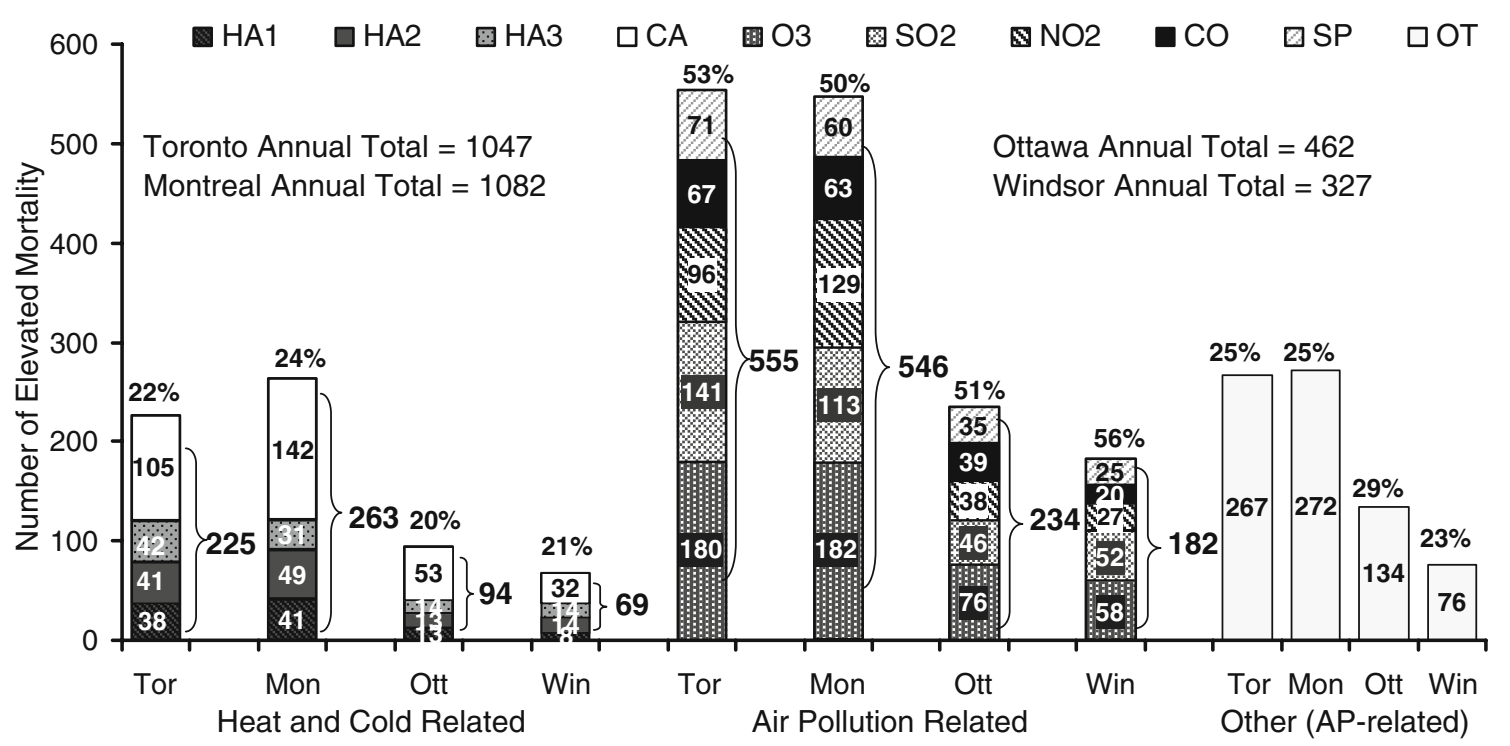

Fig. 6 Mean annual total elevated non-traumatic mortality caused by heat/cold and air pollutants in four cities (1954-2000). HA1, HA2, and $H A 3$ represent three hot weather groups; $C A$ is the cold weather group; $\mathrm{O}_{3}, \mathrm{NO}_{2}, \mathrm{SO}_{2}, \mathrm{CO}$, and $\mathrm{SP}$ are different air pollutant-related weather

groups; and OT is the "other" weather group. Tor, Mon, Ott, and Win represent the four cities: Toronto, Montreal, Ottawa, and Windsor. Legend "left-to-right" is equivalent to bars "bottom-to-top" 
there is no evidence of clear thresholds of pollutant concentrations associated with increased elevated mortality.

In addition to annual total elevated mortality counts, the daily mean elevated mortality breakdown by the ten weather groups was examined for the four cities. As Fig. 7 illustrates, daily mean elevated mortality was much higher for the extreme temperature-related weather groups than it was for either the air pollution-related or "other" weather groups, especially in Montreal and Toronto. In these two larger cities, daily mean elevated mortality counts within the extreme hot weather group were twice as high as those within "other" weather group. The smaller difference between daily elevated mortalities associated with extreme temperatures and air pollution in Ottawa and Windsor might be due to the small number of daily mortality counts. To more effectively analyze health impacts of extreme temperatures and air pollution for the smaller cities, more research should be conducted using a larger daily sample size of health outcomes, such as hospital admissions and emergency room visits.

\section{Conclusions}

A major goal of this study has been to analyze the differential and combined impacts of extreme temperatures and air pollution on human mortality for four selected cities (Montreal, Ottawa, Toronto, and Windsor) in south-central Canada. The major findings from this study were summarized as follows:

- The annual average number of elevated mortality attributable to extreme temperatures and acute exposure to air pollution, based on 1954-2000, was 1,082 [95\% confidence interval (CI) of 1,017-1,147] for Montreal, 1,047 (CI 994-1,100) for Toronto, 462 (CI 438-486) for Ottawa, and 327 (CI 311-343) for Windsor.

- Of this elevated mortality, extreme temperatures were usually associated with over $20 \%$ across the study area; air pollution was related to the remaining $80 \%$.

- Of air pollution-related elevated mortality, three pollutants $\left(\mathrm{O}_{3}, \mathrm{SO}_{2}\right.$, and $\left.\mathrm{NO}_{2}\right)$ were associated with about $75 \%$ across the study area. The remaining $25 \%$ was almost evenly associated with SP and CO, the other two pollutants included in the study. Of the five pollutants, $\mathrm{O}_{3}$ was most highly associated with elevated mortality in each of the cities, accounting for one-third of total air pollution-related mortality.

- Daily mean heat-related mortality was much higher than that associated with air pollution-related and other weather groups, especially in Montreal and Toronto. Daily mean elevated mortality within the extreme hot
Fig. 7 Daily mean elevated mortality breakdown by weather groups: the top panel for Toronto and Montreal and the bottom panel for Windsor and Ottawa (1954-2000). HA1, $H A 2$, and $H A 3$ represent three hot weather groups; $C A$ is the cold weather group; $\mathrm{O}_{3}, \mathrm{NO}_{2}$, $\mathrm{SO}_{2}, \mathrm{CO}$, and $\mathrm{SP}$ are different air pollutant-related weather groups; and OT is the "other" weather group
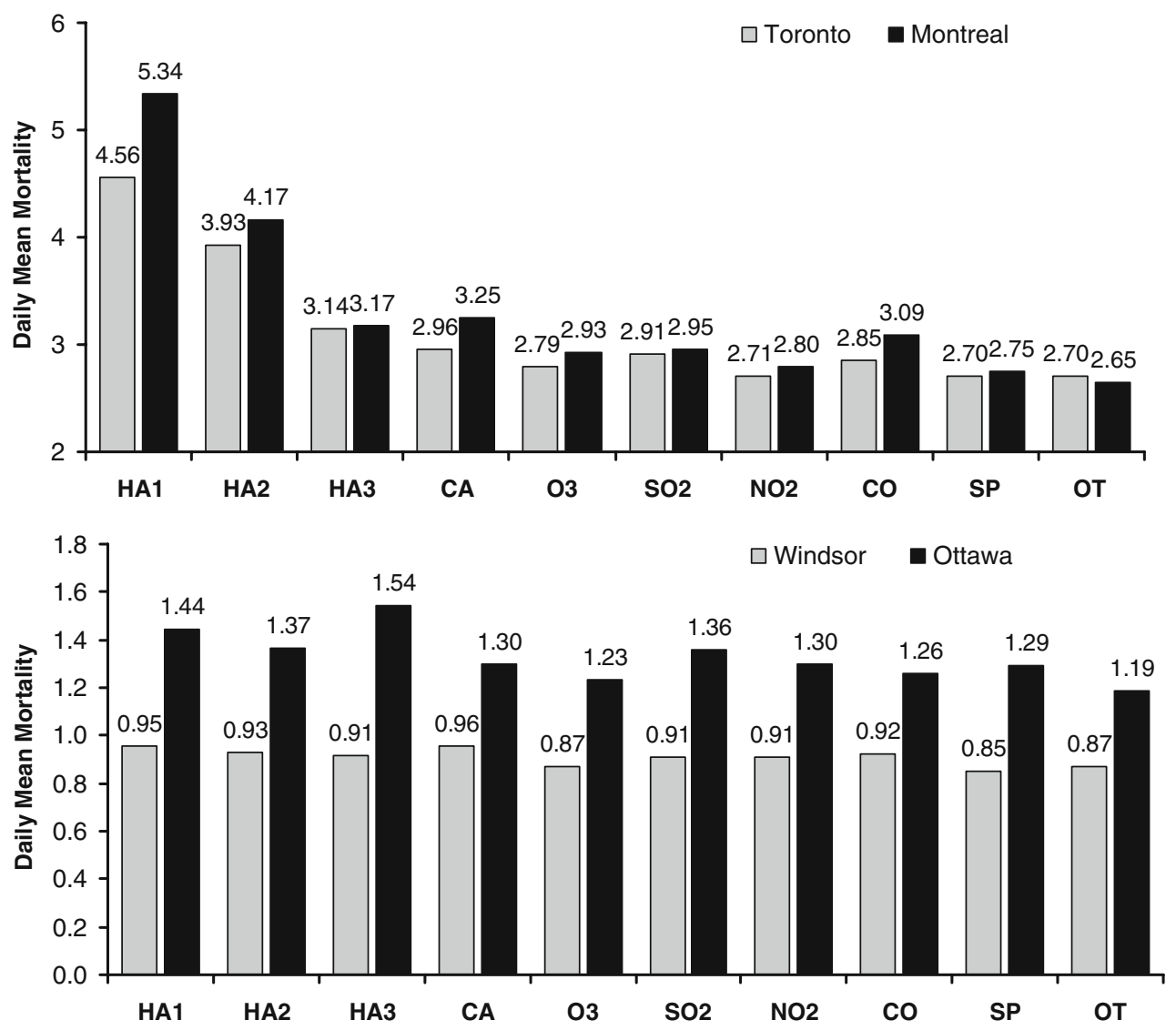
weather group in Montreal (5.3; CI 4.7-5.9) and Toronto (4.6; CI 4.1-5.1) was twice as high as that associated with "other" weather group (2.7; CI 2.5-2.9).

A general conclusion from this study is that a combination of synoptic weather typing and mortality baseline approaches can be useful to distinguish health impacts of temperature extremes and air pollution concentrations. This study aims to provide decision makers with scientific information needed for public policy risk identification and assessment. The results of this study, expressed as elevated mortality above the baseline associated with various factors (e.g., heat, cold, pollutants), can be used by governmental agencies and stakeholders to help them develop better policies on health protection and to balance policy decisions. The study could enhance our understanding of environmental problems related to human health. To support the recommendation of adaptation policies to reduce risks to vulnerable populations due to climate change, it is necessary to estimate possible changes in future extreme temperature- and air pollution-related mortality, which is the major objective of a companion paper (Part II, Cheng et al. 2009).

Acknowledgments This study was funded through the Health Policy Research Program, Health Canada (6795-15-2001/4400011). The views expressed herein are solely those of the authors and do not necessarily represent the views or official policy of Health Canada or Environment Canada. The authors are grateful for the suggestions made by the Project Advisory Committee, which greatly improved the study. We also would like to thank two anonymous reviewers for providing detailed comments that significantly improved the original manuscript.

Open Access This article is distributed under the terms of the Creative Commons Attribution Noncommercial License which permits any noncommercial use, distribution, and reproduction in any medium, provided the original author(s) and source are credited.

\section{References}

Applequist S, Gahrs GE, Pfeffer RL, Niu XF (2002) Comparison of methodologies for probabilistic quantitative precipitation forecasting. Weather Forecast 17:783-799. doi:10.1175/1520-0434 (2002)017<0783:COMFPQ $>2.0 . \mathrm{CO} ; 2$

Basu R, Ostro BD (2008) A multicounty analysis identifying the populations vulnerable to mortality associated with high ambient temperature in California. Am J Epidemiol 168:632-637. doi:10.1093/aje/kwn170

Boyce AJ (1996) Mapping diversity: a comparative study of some numerical methods. In: Cole AJ (ed) Numerical taxonomy. Academic, New York, pp 1-30

Burnett RT, Bartlett S, Krewski D, Roberts G, Raad-Young M (1994) Air pollution effects on hospital admissions: a statistical analysis of parallel time series. Environ Ecol Stat 1:325-332. doi:10.1007/BF00469429

Burnett RT, Brook JR, Yung WT, Dales RE, Krewski D (1997) Association between ozone and hospitalization for respiratory diseases in 16 Canadian cities. Environ Res 72:24-31. doi:10.1006/enrs.1996.3685

Burnett RT, Smith-Doiron M, Stieb D, Cakmak S, Brook J (1999) Effects of particulate and gaseous air pollution on cardiorespiratory hospitalizations. Arch Environ Health 54:130-139

Changnon SA, Kunkel KE, Reinke BC (1996) Impacts and responses to the 1995 heat wave: a call to action. Bull Am Meteorol Soc 77:1497-1506. doi:10.1175/1520-0477(1996)077<1497: IARTTH $>2.0 . \mathrm{CO} ; 2$

Cheng CS (1991) Synoptic climatological categorization and human mortality in Shanghai, China. Proc Middle S Div Assoc Am Geogr 24:5-11

Cheng CS, Campbell M, Li Q, Li G, Auld H, Day N, Pengelly D, Gingrich S, Yap D (2007a) A synoptic climatological approach to assess climate impact on air quality in south-central Canada. Part I: historical analysis. Water Air Soil Pollut 182:131-148. doi:10.1007/s11270-006-9327-3

Cheng CS, Campbell M, Li Q, Li G, Auld H, Day N, Pengelly D, Gingrich S, Yap D (2007b) A synoptic climatological approach to assess climate impact on air quality in south-central Canada. Part II: future estimates. Water Air Soil Pollut 182:117-130. doi:10.1007/s11270-006-9326-4

Cheng CS, Campbell M, Li Q, Li G, Auld H, Day N, Pengelly D, Gingrich S, Klaassen J, MacIver D, Comer N, Mao Y, Thompson W, Lin H (2009) Differential and combined impacts of extreme temperatures and air pollution on human mortality in southcentral Canada. Part II: future estimates. Air Qual Atmos Health doi:10.1007/s11869-009-0026-2

Cheng CS, Kalkstein LS (1997) Determination of climatological seasons for the East Coast of the U.S. using an air mass-based classification. Clim Res 8:107-116. doi:10.3354/cr008107

Cheng CS, Lam KC (2000) Synoptic typing and its application to the assessment of climatic impact on concentrations of sulfur dioxide and nitrogen oxides in Hong Kong. Atmos Environ 34:585-594. doi:10.1016/S1352-2310(99)00194-6

Davis JC (1986) Statistics and data analysis in geology, 2nd edn. Wiley, New York, p 646

Davis RE, Knappenberger PC, Michaels PJ, Novicoff WM (2003) Changing heat-related mortality in the United States. Environ Health Perspect 111:1712-1718

DeGaetano A (1996) Delineation of mesoscale climate zones in the northeastern United States using a novel approach to cluster analysis. J Clim 9:1765-1782. doi:10.1175/1520-0442(1996) 009<1765:DOMCZI $>2.0 . C O ; 2$

Dessai S (2002) Heat stress and mortality in Lisbon Part I. Model construction and validation. Int J Biomet 47:6-12. doi:10.1007/ s00484-002-0143-1

Dockery DW, Schwartz J, Spengler JD (1992) Air pollution and daily mortality: association with particulates and acid aerosols. Environ Res 59:362-373. doi:10.1016/S0013-9351(05)80042-8

Fung KY, Luginaah I, Gorey KM, Webster G (2005) Air pollution and daily hospital admissions for cardiovascular diseases in Windsor, Ontario. Can J Public Health 96:29-33

Goldberg MS, Burnett RT, Valois MF, Flegel K, Bailar JC III, Brook J, Vincent R, Radon K (2003) Associations between ambient air pollution and daily mortality among persons with congestive heart failure. Environ Res 91:8-20. doi:10.1016/S0013-9351(02) 00022-1

Guest CS, Willson K, Woodward AJ, Hennessy K, Kalkstein LS, Skinner C, McMichael AJ (1999) Climate and mortality in Australia: retrospective study, 1979-1990, and predicted impacts in five major cities in 2030. Clim Res 13:1-15. doi:10.3354/ cr013001

Hu W, Mengersen K, McMichael A, Tong S (2008) Temperature, air pollution and total mortality during summers in Sydney, 1994-2004. Int J Biometeorol 52:689-696. doi:10.1007/s00484-008-0161-8 
Jolliffe IT (1986) Principal component analysis. Springer, New York, p 271

Judek S, Jessiman B, Stieb D, Vet R (2004) Estimated number of excess deaths in Canada due to air pollution. http://www.hc-sc. gc.ca/ahc-asc/media/nr-cp/2005/2005_32bk2_e.html (accessed February 2008)

Kalkstein LS (1991) A new approach to evaluate the impact of climate on human mortality. Environ Health Perspect 96:145-150. doi: $10.2307 / 3431223$

Kalkstein LS, Greene JS (1997) An evaluation of climate/mortality relationships in large U.S. cities and the possible impacts of a climate change. Environ Health Perspect 105:84-93. doi: $10.2307 / 3433067$

Kalkstein LS, Nichols MC, Barthel CD, Greene JS (1996) A new spatial synoptic classification: application to air-mass analysis. Int J Climatol 16:983-1004. doi:10.1002/(SICI)1097-0088 (199609)16:9<983::AID-JOC61>3.0.CO;2-N

Kalkstein LS, Barthel CD, Ye H, Smoyer K, Cheng CS, Greene JS, Nichols MC, Kalkstein AJ (1997) The impacts of weather and pollution on human mortality. Publ In Clim L(1) p 41

Keatinge WR, Donaldson GC (2006) Heat acclimatization and sunshine cause false indications of mortality due to ozone. Environ Res 100:387-393. doi:10.1016/j.envres.2005.08.012

Lambert WE, Samet JM, Dockery DW (1998) Community air pollution. In: Rom WN (ed) Environmental and occupational medicine. Lippincott-Raven, Philadelphia, pp 1501-1522

McGregor GR, Watkin HA, Cox M (2004) Relationships between the seasonality of temperature and ischaemic heart disease mortality: implications for climate based health forecasting. Clim Res 25:253-263. doi:10.3354/cr025253

Medina-Ramón M, Schwartz J (2007) Temperature, temperature extremes, and mortality: a study of acclimatisation and effect modification in 50 US cities. Occup Environ Med 64:827-833

Nichols MC, Kalkstein LS, Cheng CS (1995) Possible human health impacts of a global warming. World Resour Rev 7:77-103

OMA (2005) Illness costs of air pollution. ICAP Summary Report. Ontario Medical Association, Toronto, p 11

Pirard P, Vandentorren S, Pascal M, Laaidi K, Le Tertre A, Cassadou S, Ledrans M (2005) Summary of the mortality impact assessment of the 2003 heat wave in France. Euro Surveill 10:153-156

Pope CA III, Kalkstein LS (1996) Synoptic weather modeling and estimates of the exposure-response relationship between daily mortality and particulate air pollution. Environ Health Perspect 104:414-420. doi: $10.2307 / 3432686$

Qian Z, He Q, Lin HM, Kong L, Bentley CM, Liu W, Zhou D (2008) High temperatures enhanced acute mortality effects of ambient particle pollution in the "oven" City of Wuhan, China. Environ Health Perspect 116:1172-1178

Rainham DGC, Smoyer-Tomic KE (2003) The role of air pollution in the relationship between a heat stress index and human mortality in Toronto. Environ Res 93:9-19. doi:10.1016/S0013-9351(03) 00060-4

Rocklöv J, Forsberg B (2008) The effect of temperature on mortality in Stockholm 1998-2003: a study of lag structures and heatwave effects. Scand J Public Health 36:516-523. doi:10.1177/ 1403494807088458

Ross T, Lott N (2003) A Climatology of 1980-2003 Extreme Weather and Climate Events. National Climate Data Center Technical Report No. 2003-01, p 14

Schwartz J (2000) Assessing confounding, effect modification, and thresholds in the association between ambient particles and daily deaths. Environ Health Perspect 108:563-568. doi:10.2307/ 3454620

Schwartz J, Spix C, Wichmann HE, Malin E (1991) Air pollution and acute respiratory illness in five German communities. Environ Res 56:1-14. doi:10.1016/S0013-9351(05)80104-5

Sheridan SC, Kalkstein LS (2004) Progress in heat watch-warning system technology. Bull Am Meteorol Soc 85:1931-1941. doi:10.1175/BAMS-85-12-1931

Shin HH, Stieb DM, Jessiman B, Goldberg MS, Brion O, Brook J, Ramsay T, Burnett RT (2008) A temporal, multicity model to estimate the effects of short-term exposure to ambient air pollution on health. Environ Health Perspect 116:1147-1153

Stieb DM, Burnett RT, Beveridge RC, Brook JR (1996) Association between ozone and asthma emergency department visits in Saint John, New Brunswick, Canada. Environ Health Perspect 104:1354-1360. doi:10.2307/3432974

Toronto Public Health (2001) Toronto air quality index health links analysis. Technical Report. Toronto Public Health, Toronto, p 40

Toronto Public Health (2004) Air pollution burden of illness in Toronto: 2004 summary. Technical Report. Toronto Public Health, Toronto, p 19

Vedal S, Brauer M, White R, Petkau J (2003) Air pollution and daily mortality in a city with low levels of pollution. Environ Health Perspect 111:45-51

Wong CM, Vichit-Vadakan N, Kan H, Qian Z, the PAPA Project Teams (2008) Public health and air pollution in Asia (PAPA): a multicity study of short-term effects of air pollution on mortality. Environ Health Perspect 116:1195-1202

World Health Organization (2004) Health aspects of air pollution: results from the WHO project "systematic review of health aspects of air pollution in Europe." World Health Organization, Report E83080. WHO Regional Office for Europe, Copenhagen, p 24 